\title{
Advances in gastrointestinal manometry studies in children
}

Alejandro Llanos-Chea and Samuel Nurko*

Department of Gastroenterology, Center for Motility and Functional Gastrointestinal Disorders, Boston Children's Hospital, Boston, MA, USA

\section{RESUMEN}

Los trastornos de la motilidad gastrointestinal (GI) en niños pueden ir desde procesos relativamente benignos, como la enfermedad por reflujo gastroesofágico o el estreñimiento funcional, hasta trastornos más graves como la acalasia, la enfermedad de Hirschsprung y la pseudoobstrucción intestinal. Un enfoque sistemático para niños con posibles trastornos de motilidad debe excluir problemas anatómicos y enfermedades subyacentes, así como mostrar alteraciones en los patrones de tránsito y motilidad. La tecnología para medir la motilidad GI ha evolucionado con el tiempo, y las nuevas técnicas incluyen la manometría de alta resolución que se puede implementar junto con la tecnología de impedancia. Estas nuevas tecnologías han permitido una mejor comprensión de la fisiopatología de los trastornos de la motilidad y la implementación de nuevas terapias. (NeuroGastroLatam Rev. 2018;2:51-63)

Corresponding author: Samuel Nurko, samuel.nurko@childrens.harvard.edu

Palabras clave: Motilidad. Niños. Manometría de alta resolución. Pseudobstrucción. Enfermedad de hirschsprung. 


\section{ABSTRACT}

Gastrointestinal (GI) motility disorders in children can range from relatively benign processes such as gastroesophageal reflux disease or functional constipation to more serious disorders such as achalasia, Hirschsprung's disease, and intestinal pseudo-obstruction. A systematic approach to children with possible motility disorders needs to exclude anatomic problems, underlying diseases, and show alterations in transit and motility patterns. The technology to measure GI motility has evolved over time, and new techniques include high-resolution manometry that can be implemented together with impedance technology. These new technologies have allowed a better understanding of the pathophysiology of motility disorders and the implementation of new therapies.

Key words: Motility. Children. High-resolution manometry. Pseudo-obstruction. Hirschsprung's disease.

\section{INTRODUCTION}

The motility of the gastrointestinal (GI) tract encompasses many steps that include the ingestion of nutrients and their transport along specific areas of the GI tract so they can be digested and absorbed and finally allows the remnants to be expelled when needed in a socially acceptable manner ${ }^{1,2}$.

Complex interaction between the muscles, the myenteric plexus, the peripheral nervous system, and the brain result in specific motility patterns in every area of the GI tract. Disorders that affect the GI motility in children are common ${ }^{1,3}$. These disorders can result from primary diseases affecting the nervous innervation and muscles of the GI tract (achalasia, gastroparesis, pseudo-obstruction, and Hirschsprung disease [HD]), and secondary to different conditions as congenital malformations that alter the motility function (i.e., tracheoesophageal fistula), pediatric conditions that lead to motility alterations (i.e., gastroesophageal reflux disease), or secondary to of non-GI conditions (i.e., systemic disease as scleroderma).

When evaluating a pediatric patient with symptoms suggesting that there may be a GI motility disorder, excluding an anatomic cause is the most important first step after a careful history and physical examination. This is usually done with the use of radiographic and/or endoscopic studies. Before embarking on an extensive motility evaluation, attempts to correct any underlying disease or metabolic abnormality should be done first because the treatment of the underlying condition may result in normalization of the motility problem. The performance of transit studies is the next step and important as it provides objective data that show how movement may be altered throughout the different segments of the GI tract and may indicate fast, slow, or normal transit measurements 0that have clinical implications as the 
TABLE 1. Evaluation of a patient with suspected motility disorder

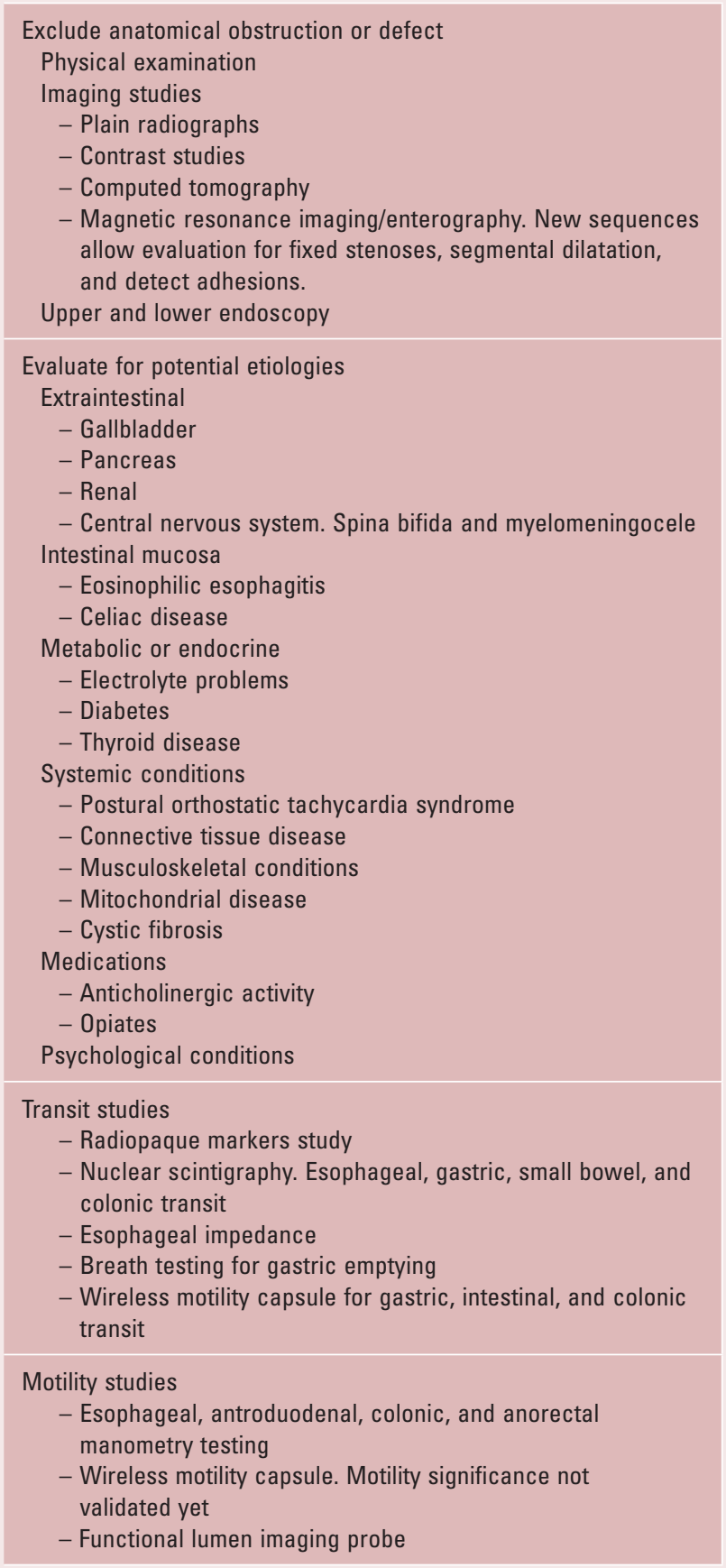

Adapted from Nurko S, $2017^{6}$.

treatment varies accordingly ${ }^{2,4-6}$ (Table 1). After an anatomic problem has been excluded, and transit abnormalities have been documented, the next step in the evaluation is the performance of motility studies.
The present article will focus on the most recent advances in GI manometry studies and techniques in children.

\section{MANOMETRY STUDIES}

Each digestive organ has a characteristic motility pattern that has evolved to provide the most efficient motor function ${ }^{1,2,4,5,7}$. Overall, manometric studies directly evaluate the contractile patterns of the different segments of the GI tract and allow the definition of the underlying pathophysiology by demonstrating if the alteration is in the muscle strength or the nerve regulation ${ }^{1,2,4,5,7}$. GI manometry provides direct evidence about the contractile events of the organ that is studied. Over the past years, GI manometry has evolved from being considered a research technique to a useful diagnostic tool $1^{1,4,8-10}$.

The role of manometric evaluation in children has been more clearly defined for anorectal manometry (ARM), esophageal manometry (EM), antroduodenal manometry (ADM), and colonic manometry $(\mathrm{CM})^{1,4,8-10}$. The performance of motility studies in the pediatric population has certain important characteristics that make this more challenging including technical aspects related to catheter size as well as developmental abnormălities and cooperation $^{1,8,11}$.

Since pediatric manometric studies have not been performed in asymptomatic controls, normal values have been defined after children that undergo testing is deemed normal and with comparison with adult parameters. Considering this limitation, it is crucial to understand that different manometry studies 


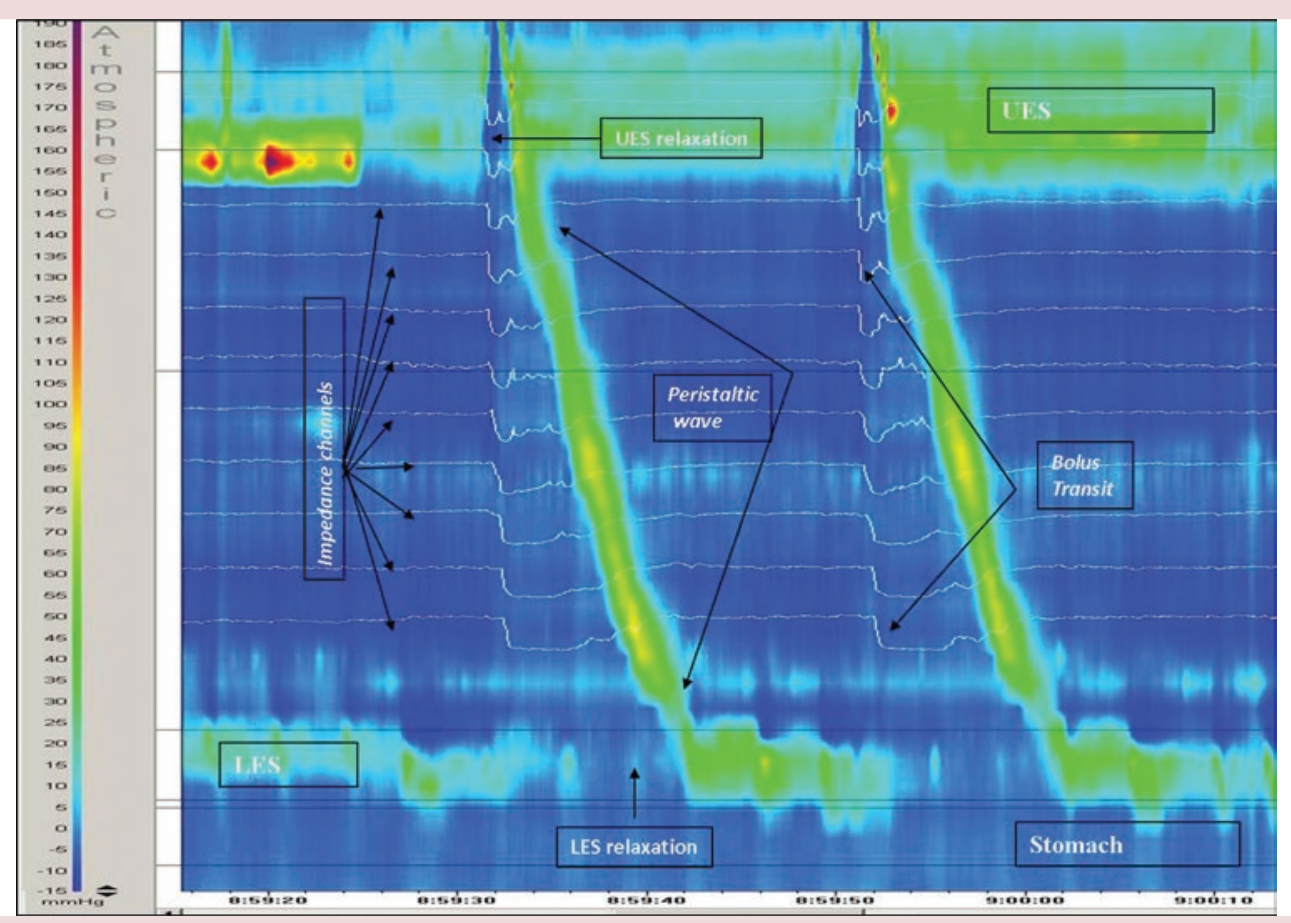

FiguRE 1. Esophageal manometry with impedance. This represents a normal esophageal manometry using high-resolution manometry. Normal relaxations of the upper esophageal and lower esophageal sphincter can be seen, as can the peristaltic wave. The tracing also has impedance waves that allow the measurement of bolus transit (adapted from Nurko S, 20176).

could identify abnormalities that maybe be non-specific from a clinical standpoint, and caution needs to be taken to avoid overinterpretation $^{1,12,13}$.

In recent years, high-resolution manometry (HRM) was developed, leading to major technical advances ${ }^{7,10,14}$ (Figs. 1-4). The HRM technology gathers more data by increasing the number of recording sites and decreasing the spacing between them. These data are transformed into contour plots using a specialized software. These plots allow a better definition of the intraluminal pressure environment without spatial gaps and with minimal movement-related artifacts ${ }^{15,16}$. HRM has become the standard for EM, ARM, and recently for antroduodenal and colonic studies ${ }^{10}$. The main impact of HRM in children is that it has made manometric studies more tolerable, easier to perform, and has also simplified the placement of the catheters ${ }^{16}$. Recently, it has also been shown to provide better diagnosis, particularly when studying the esophagus ${ }^{6}$.

\section{EM}

EM consists of the measurement of pressure events in the esophagus following test swallows ${ }^{17}$. EM evaluates dysphagia, chest pain, and chronic regurgitation. HRM (24 or 36 sensors, $1 \mathrm{~cm}$ apart) has replaced standard manometry (4-8 pressure sensors, $3-5 \mathrm{~cm}$ apart) (Fig. 1). It has had the biggest impact in the study of esophageal motor function and is currently the gold standard test to evaluate esophageal function in children ${ }^{6,7,11,16,18,19}$. 


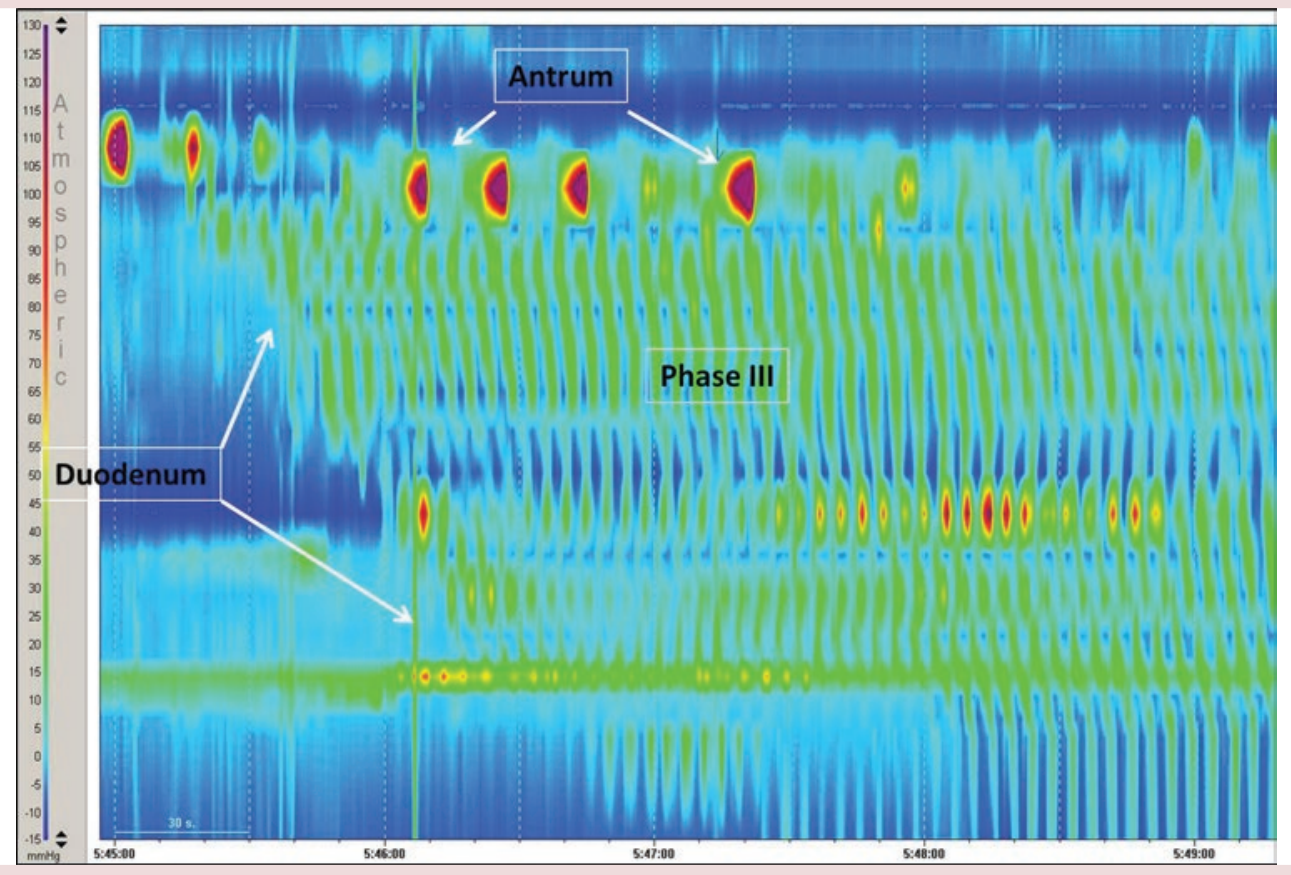

Figure 2. Normal high-resolution antroduodenal manometry. A Phase III of the motor migrating complex can be appreciated starting in the antrum ( 3 cycles/min and migrating distally into the small bowel (12 cycles/min) (adapted from Nurko S, 20176).

Standard manometry required repeated catheter adjustments, while the increased number of HRM sensors allows for simultaneous measurement of pharynx, esophagus, and stomach. More recently, impedance has been added into the catheter, allowing the study the interrelationship between bolus flow, peristalsis, and sphincter opening7. The current indications for EM are listed in table 2.

Solid-state catheters are more commonly used, but perfused catheters are also available. The addition of impedance sensors and available smaller diameter catheters (6 French) is more recent advances. Normal values are variable among systems and not equivalent when using different brands ${ }^{14}$.

On interpretation, HRM will be used to evaluate the three functional areas of the esophagus: upper esophageal sphincter (UES), esophageal body, and lower esophageal sphincter (LES) ${ }^{19}$ (Fig. 1). The Chicago classification (CC), developed in adults, defined and incorporated new parameters of esophageal motility and is used as well in children $7,11,14,18$. By combining the analysis obtained from the individual swallows ${ }^{19}$, the CC provides uses a hierarchical approach to provide a diagnosis; it first focuses on the esophagogastric junction (EGJ) to establish if there is outflow obstruction, followed by the evaluation of peristaltic sequences, dividing the problems either in major or minor peristaltic disorders depending on the alterations ${ }^{14}$.

The application of the CC criteria to pediatric patients needs to be done with caution, to avoid incorrect diagnoses. Studies have demonstrated the need for size and age adjustment 


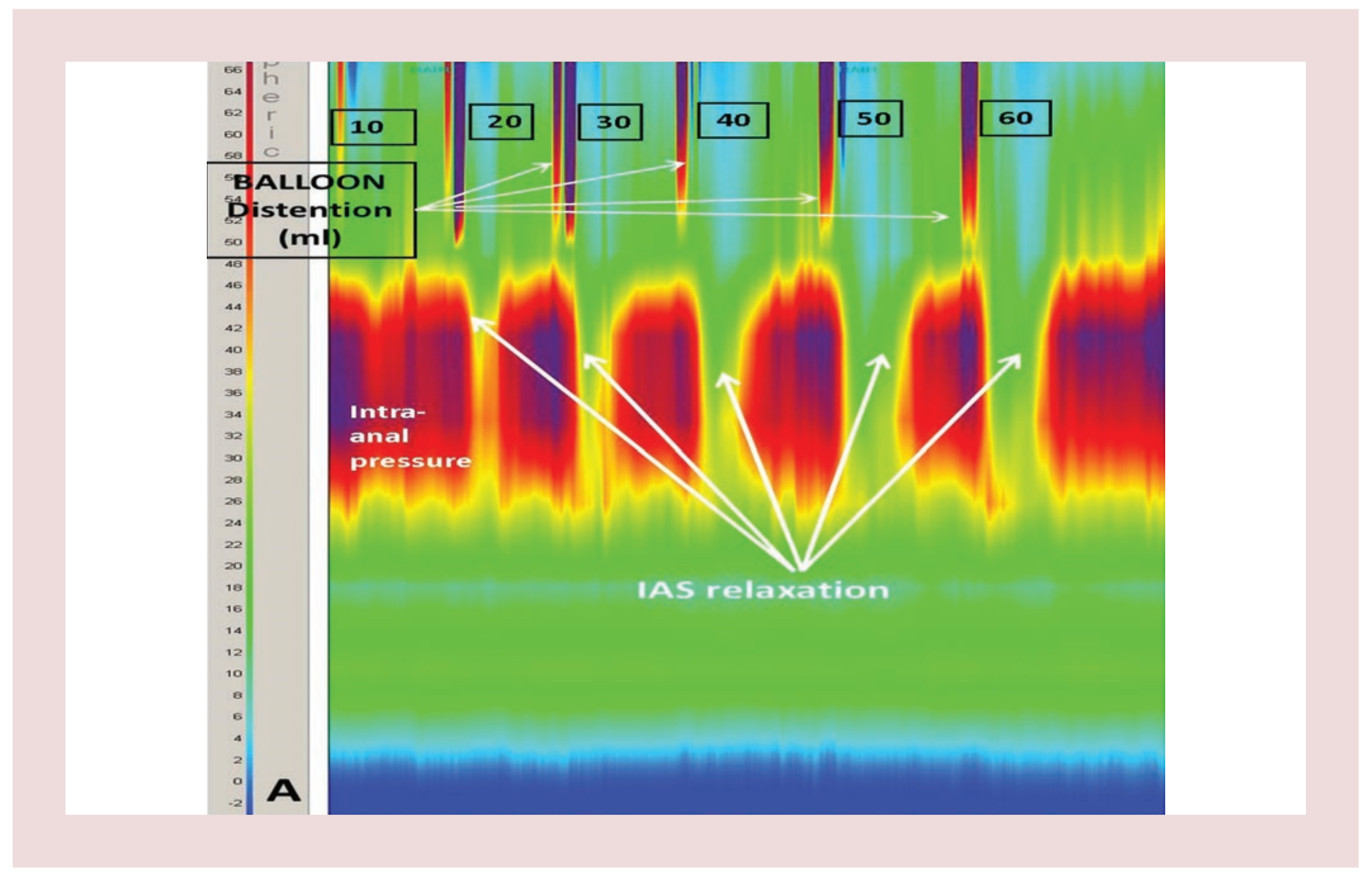

FIgURE 3. Anorectal manometry showing normal relaxation of the internal anal sphincter after balloon distention. A normal dose-response curve can be seen.

in children ${ }^{11,18}$. In one study, when measurements were adjusted for size and age, the percentage of patients with a definable motility disorder decreased from 66\% (using adult criteria) to $53 \%$ and $50 \%$, respectively, when adjusting for pediatric factors ${ }^{18}$. This is important as treatment selection can vary if these adult CC criteria are used. Future studies to define normal values in children are needed ${ }^{6}$.

The capacity of studying the relationship between motility events and esophageal bolus flow was achieved when impedance measurements were added to HRM (high resolution manometry with impedance, HRIM) ${ }^{6}$ (Fig. 1). Impedance helps to define the relationship between motor events and bolus transit ${ }^{19}$. Impedance abnormalities are not part of the CC. Pressure flow analysis has been incorporated as an objective parameter using impedance and pressure ${ }^{20}$ to estimate for UES dysfunction, degree of LES obstruction, and identify patients with subtle dysmotility ${ }^{7,21,22}$. The dysphagia risk and the swallow risk index, used to predict aspiration in adults and children, can be calculated using the automated impedance manometry (AIM) analysis ${ }^{20}$. Other proposed parameters include the bolus presence time (BPT) defined as the duration of bolus presence within the EGJ, and the bolus flow time (BFT), which is trans-EGJ-BFT ${ }^{23,24}$. The BFTto-BPT ratio (BFT/BPT) delineates the successful trans-EGJ emptying relative to the $\mathrm{BPT}^{23-25}$. In adults and to some extent in 


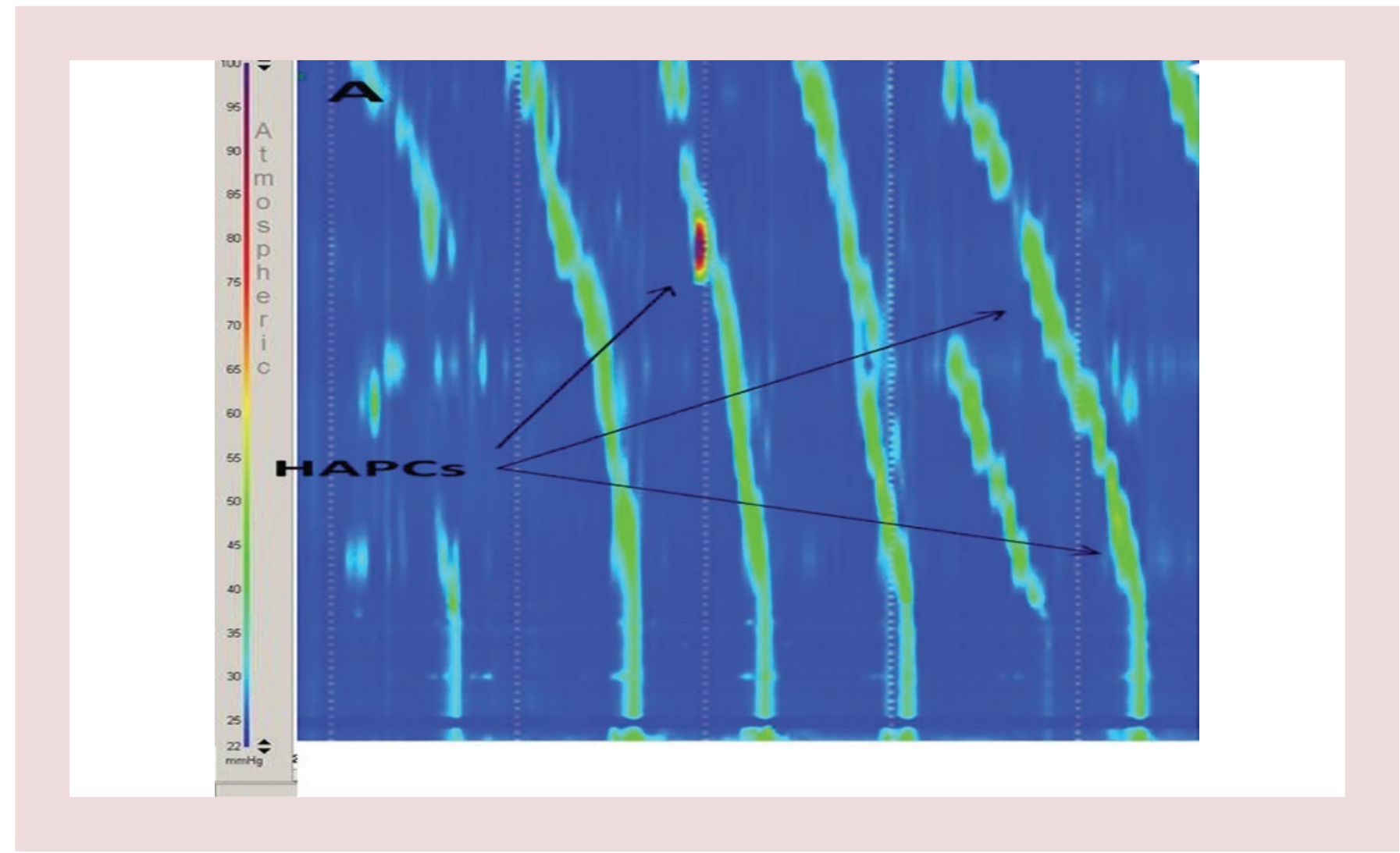

Figure 4. High-resolution colonic manometry. The figure shows a normal study with the presence of high amplitude propagating contractions migrating from the cecum all the way down to the rectosigmoid.

children, these measurements have been shown to correlate with the severity of dysphagia, achalasia type, and therapeutic effectiveness for EGJ obstruction ${ }^{21,23-25}$. In children, AIM analysis may be applied to discriminate the causes of dysphagia ${ }^{7}$ and to differentiate if post-operative dysphagia is present in pediatric patients' status post-fundoplication ${ }^{26}$.

In addition, HRM and HRIM have significantly changed clinical management in special pediatric conditions as rumination, esophageal atresia (particularly with persistent symptoms including dysphagia), and for consideration of fundoplication ${ }^{19}$.

\section{ADM}

$\mathrm{ADM}$ registers the intraluminal pressure, amplitude, and coordination in the antrum and the proximal small intestine, being capable to evaluate the motor function of the foregut. This allows an understanding of stomach and small intestine neuromuscular disorders of the stomach and small bowel ${ }^{4,8,27,28} . \mathrm{ADM}$ discriminates between a real motility disorder from factitious disorders in patients that present with concern for intestinal failure ${ }^{4,8,13}$. Finding a normal ADM in patients with severe pain and inability to eat is one of the most important contributions of the test, as it can redirect therapy away from a motility disorder. ADM solid-state and perfused HRM 
TABle 2. Indications for manometry studies ${ }^{10,19}$.

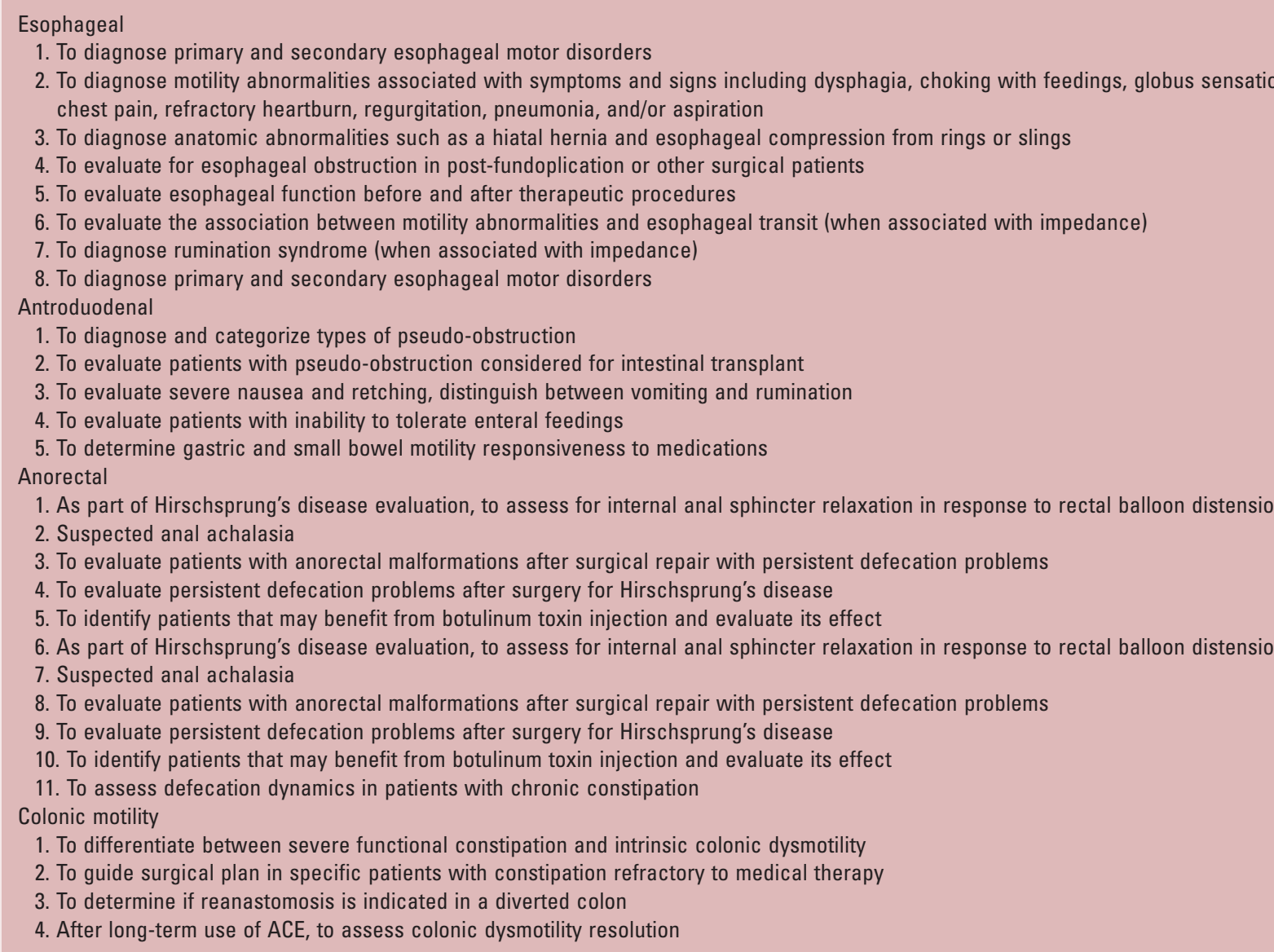

ACE: antegrade continence enemas

catheters are now available, although most institutions still use traditional perfused catheters $^{29}$.

The configuration of the catheter will be based on the mapping precision required and the age of the patient ${ }^{8}$. Usually perfused manometry catheters use eight pressure sensors with varying distances between them (3 and $10 \mathrm{~cm}$ ). These catheters are widely available and are relatively inexpensive ${ }^{29}$. HRM perfused catheters have 36 pressure ports, $2-3 \mathrm{~cm}$ apart with the distal port spaced further for a deeper reach into the small intestine (Fig. 2). Most ADM catheters have a built-in central lumen utilized both for glide wire placement and for post-pyloric feeds administration, if needed. HRM solid-state catheters have similar configuration as the HRM perfused ones provide pressure topography plots and are useful to avoid electrolyte imbalance problems. Nevertheless, their use is limited due to high cost and lack of standardized values in normal children ${ }^{19}$.

The hallmark of intestinal integrity is the presence of a Phase III of the motormigrating complex (MMC) during fasting (Fig. 2). The lack of the antral component of Phase III is not strictly abnormal since one-third to half of the Phase III contractions can start distal to the stomach $^{4,30}$. Neuropathic and myopathic pseudo-obstruction can be defined by analyzing the characteristics of the $\mathrm{MMC}$, response to 
feedings or provocative medications (such as erythromycin and octreotide). Manometry can also be used to predict outcome ${ }^{31,32}$. The presence of the MMC can help to predict failure to enteral feeds tolerability and/or response to prokinetics ${ }^{33}$.

\section{ARM}

ARM permits the assessment of the rectoanal reflexes, sensory anorectal responses, anal sphincter length, anal pressure and function, and defecation dynamics ${ }^{10}$ (Fig. 3). As the most common motility test performed in children, the ARM probes have evolved from the standard water perfused to HRM catheters, and even more advanced high definition catheters (three dimensional [3D]) probes ${ }^{10}$. The water perfusion catheter uses $4-8$ pressure sensors, $0.5 \mathrm{~cm}-1 \mathrm{~cm}$ apart, with a central channel and a balloon at its tip. The HRM solid-state catheter usually has eight closely spaced sensors. As with HRM EM and ADM, pressure topography plots are possible ${ }^{10}$. The solid 3D probe has 256 radially oriented microtransducers. This configuration generates a 3D pressure plot of the anal canal that results in topographical representations of the entire length and circumference of the anal canal during defecation maneuvers and squeeze $\mathrm{e}^{9,34}$.

The main interpretation of the ARM includes measuring the baseline anal resting pressure and the presence of normal rectoanal inhibitory reflex (RAIR). Pressure calculation and RAIR correlate between standard and HRM ARM, but 3D HRM reports higher mean resting pressure and mean squeeze pressure on comparison with water-perfused $\mathrm{ARM}^{35}$.
Normative data for the 3D evaluation recently established a resting pressure of $83 \pm 23 \mathrm{mmHg}$, and a mean balloon volume, to evoke a RAIR, of $15.7 \pm 10.9 \mathrm{~mL}^{36}$.

ARM most common indication in children is the evaluation of RAIR to help exclude HD ${ }^{10}$ (Fig. 3, Table 2). The RAIR is present in children with spinal cord lesions, but the presence of anal spasms and prolonged maximum relaxation of the anal sphincter with low inflated balloon volumes has been associated with neuropathy. To consider that testing for this defecation, dynamics may be falsely abnormal in children due to the position during the test and associated anxiety to defecation attempt in the presence of the medical providers ${ }^{37}$.

\section{CM}

$\mathrm{CM}$ is possibly the only manometry test performed more in children than in adults ${ }^{38}$ and is a valuable diagnostic tool children with severe defecation disorders. $\mathrm{CM}$ has become now widely available in North American major pediatric referral centers ${ }^{10}$. $\mathrm{CM}$ registers the intraluminal colonic pressure and coordination allowing us to learn the colon physiology at various pediatric age groups ${ }^{10}$. The American Neurogastroenterology and Motility Society (ANMS) has recommended CM for severely constipated children non-responsive to maximized medical and behavioral therapy ${ }^{4}$.

$\mathrm{CM}$ catheters can be water perfused or solid state, having a range of 6-36 pressure sensors, 1-15 apart from each other depending on the size. It has been described that pressure topography plots from solid-state catheters have better 
sensitivity to spot high amplitude propagated contractions (HAPCs) compared to water-perfused catheters ${ }^{39}$ or conventional tracings ${ }^{40}$. In addition, water-perfused systems could cause water overload and electrolyte disturbances ${ }^{10}$.

To date, there are no prospective controlled studies evaluating $\mathrm{CM}$ results and their ability to indicate response to therapeutic interventions or predict clinical outcomes. A pediatric retrospective study included $150 \mathrm{CM}$, of which normal colonic motility was found in $38 \%$ of children, left colon dysmotility in $17 \%$, and total colonic dysmotility in the rest. Based on the results of the study, treatment changes were recommended in $93 \%$ of patients, resulting in symptom improvement in $78 \%$ and worsening in $4 \%^{41}$.

The ANMS consensus main indications for $\mathrm{CM}$ are described in table 2. The test should be used to identify presence and quality of the HAPCs and the gastrocolic response. A recent study correlated manometric findings with histological abnormalities to see if the manometric patterns could be used to predict neuropathy versus myopathy. They did not show correlation between manometric and histologic findings, indicating that more work is need$\mathrm{ed}^{42}$. CM has been able to predict outcomes for antegrade colonic enemas ${ }^{43,44}$ and can aid in directing surgical interventions like the performance of a diverting ileostomy. The use of segmental motility abnormalities cannot be used to suggest partial colonic resections, as the results have been variables ${ }^{45-48}$.

$\mathrm{CM}$ in combination with ARM has emerged as an important tool in understanding the pathophysiology and guiding the management of persistent post-operative symptoms of patients with HD and anorectal malformations such as imperforate anus ${ }^{10}$.

Normal colon motility patterns have been generated from observations of pediatric patients that were studied and then diagnosed clinically as normal ${ }^{49}$. During fasting, differently from recognizable tracings in the upper GI tract, colon contracts are low amplitude, non-propulsive, segmental, and sparse ${ }^{50}$. Even though feeding increases colonic tone and contractions improve, the most clinically significant contraction pattern occurs in response to bisacodyl administration. There is agreement that a normal CM study is diagnosed when HAPCs are present and propagated to the rectosigmoid junction spontaneously, induced by meal or by bisacodyl $1^{4}$.

Recent advances have allowed a better characterization of colonic function. There are new fiber-optic catheters that allow the use of 72-90 sensors (up to 144 sensors), having sensors $1 \mathrm{~cm}$ apart throughout the colon ${ }^{51-53}$. At present, the catheter is not commercially available and analysis of such large volume of physiological data has not been validated. For that reason, more clinical studies will be helpful to define the way this technology applies into clinical practice. These catheters have not been evaluated in children ${ }^{54}$.

\section{OTHER ADVANCES IN THE EVALUATION OF MOTILITY DISORDERS}

\section{Wireless motility capsule (WMC)}

New technology with the advent of wireless technology has provided non-invasive 
measurements of GI motility. The WMC can measure the gastric emptying time, small bowel, and colon transit time. Ingested by mouth, the system consists of a single-use, non-digestible capsule, a receiver, and data processing software. During the capsule passage, temperature, $\mathrm{pH}$, and pressure are continuously recorded and transmitted to an external radioreceiver ${ }^{55}$. Obstruction, capsule retention, and failure to confirm capsule expulsion from the body constitute potential serious adverse events. An estimated rate of $0.01 \%$ of capsules retention that required an intervention has been suggested $^{56}$.

The WMC has the potential of avoiding the need for invasive motility testing ${ }^{57}$, but more information is needed ${ }^{58}$.

\section{FUNCTIONAL LUMEN IMAGING PROBE (FLIP)}

The endoluminal (endo)-FLIP is one of the newest available techniques to assess GI motility function. The endo-FLIP enables the evaluation of distensibility and compliance of hollow organs and sphincters, and may provide insight into motility function too. Data in children are non-existent ${ }^{59}$.

The FLIP consists on catheter with 16 paired high-resolution planimetry electrodes (4 mm-1 cm apart) and a compliant balloon on the distal end. It can be placed into the esophagus trans-orally or trans-nasally to an awake, sedated, or under general anesthesia patient. The balloon is distended with fixed volumes of conductive fluid to provide controlled dilatation. Electrodes measure a cross-sectional area along an axial plane obtaining luminal dimensions and distensibility in real time 60,61 .

The Endoflip ${ }^{\circledR}$ system and its accessory catheters have the US Food and Drug Administration clearance for clinical use as a pressure and dimension measurement device, as an adjunctive test in patients with symptoms consistent with GI motility disorders ${ }^{61,62}$. As this technique has been utilized to assess the mechanical properties of the esophageal wall and opening dynamics of the EGJ, this new information has been focused in achalasia and eosinophilic esophagitis ${ }^{60}$. In addition, complementary clinical information to the standard achalasia evaluation with HRM is also becoming available by assessing esophageal contractility ${ }^{63,64}$.

\section{CONCLUSION}

Over the past years, technology has allowed a more detailed and precise study of the GI motor functions. The understanding of the value of each of these novel techniques to enhance our knowledge of the pathophysiological mechanisms of the different motility disorders in children is still evolving. These advances, initially done in adults, are slowly being translated and applied in pediatric patients. Nevertheless, it is important to keep in mind that normative data to children cannot be extrapolated that careful interpretation is needed to make the best management decisions toward patient care. Manometry testing is a helpful tool, but it should be part of a whole evaluation of the patient. 


\section{REFERENCES}

1. Nurko S. Gastrointestinal manometry: methodology and indications. In: Walker's Pediatric Gastrointestinal Disease: Physiology, Diagnosis, Management. $5^{\text {th }}$ ed. Philadelphia, PA: B.C. Decker Inc.; 2008.

2. Camilleri M, Hasler WL, Parkman HP, Quigley EM, Soffer E. Measurement of gastrointestinal motility in the GI laboratory. Gastroenterology. 1998;115:747-62.

3. Chumpitazi B, Nurko S. Pediatric gastrointestinal motility disorders: challenges and a clinical update. Gastroenterol Hepatol (N Y). 2008;4:140-8.

4. Camilleri M, Bharucha AE, di Lorenzo C, et al. American neurogastroenterology and motility society consensus statement on intraluminal measurement of gastrointestinal and colonic motility in clinical practice. Neurogastroenterol Motil. 2008;20:1269-82.

5. Chogle A, Saps M. Gastroparesis in children: the benefit of conducting 4-hour scintigraphic gastric-emptying studies. J Pediatr Gastroenterol Nutr. 2013;56:439-42.

6. Nurko S. Motility disorders in children. Pediatr Clin North Am. 2017; 64:593-612.

7. Rommel N, Omari TI, Selleslagh M, et al. High-resolution manometry combined with impedance measurements discriminates the cause of dysphagia in children. Eur J Pediatr. 2015;174:1629-37.

8. Di Lorenzo C, Hillemeier C, Hyman P, et al. Manometry studies in children: minimum standards for procedures. Neurogastroenterol Motil. 2002; 14:411-20.

9. Belkind-Gerson J, Tran K, Di Lorenzo C. Novel techniques to study colonic motor function in children. Curr Gastroenterol Rep. 2013;15:335.

10. Rodriguez L, Sood M, Di Lorenzo C, Saps M. An ANMS-NASPGHAN consensus document on anorectal and colonic manometry in children. Neurogastroenterol Motil. 2017;29:E12944.

11. Goldani HA, Staiano A, Borrelli O, Thapar N, Lindley KJ. Pediatric esophageal high-resolution manometry: utility of a standardized protocol and size-adjusted pressure topography parameters. Am J Gastroenterol. 2010; 105:460-7.

12. Baron HI, Beck DC, Vargas JH, Ament ME. Overinterpretation of gastroduodenal motility studies: two cases involving munchausen syndrome by proxy. J Pediatr. 1995;126:397-400.

13. Hyman PE, Bursch B, Beck D, DiLorenzo C, Zeltzer LK. Discriminating pediatric condition falsification from chronic intestinal pseudo-obstruction in toddlers. Child Maltreat. 2002;7:132-7.

14. Kahrilas PJ, Bredenoord AJ, Fox M, et al. The chicago classification of esophageal motility disorders, v3.0. Neurogastroenterol Motil. 2015; 27:160-74.

15. Bredenoord AJ, Fox M, Kahrilas PJ, et al. Chicago classification criteria of esophageal motility disorders defined in high resolution esophageal pressure topography. Neurogastroenterol Motil. 2012;24 Suppl 1:57-65.

16. Staiano A, Boccia G, Miele E, Clouse RE. Segmental characteristics of oesophageal peristalsis in paediatric patients. Neurogastroenterol Motil. 2008;20:19-26.

17. Gyawali CP, Bredenoord AJ, Conklin JL, et al. Evaluation of esophageal motor function in clinical practice. Neurogastroenterol Motil. 2013;25:99-133.

18. Singendonk MM, Kritas S, Cock C, et al. Applying the chicago classification criteria of esophageal motility to a pediatric cohort: effects of patient age and size. Neurogastroenterol Motil. 2014;26:1333-41.

19. Rosen R, Garza JM, Tipnis N, Nurko S. An ANMS-NASPGHAN consensus document on esophageal and antroduodenal manometry in children. Neurogastroenterol Motil. 2018;30:e13239.

20. Rommel N, Selleslagh M, Hoffman I, et al. Objective assessment of swallow function in children with suspected aspiration using pharyngeal automated impedance manometry. J Pediatr Gastroenterol Nutr. 2014;58:789-94.

21. Ferris L, Rommel N, Doeltgen S, et al. Pressure-flow analysis for the assessment of pediatric oropharyngeal dysphagia. J Pediatr. 2016;177:279-850.
22. Singendonk MM, Kritas S, Cock C, et al. Pressure-flow characteristics of normal and disordered esophageal motor patterns. J Pediatr. 2015;166:690-60.

23. Lin Z, Imam H, Nicodème F, et al. Flow time through esophagogastric junction derived during high-resolution impedance-manometry studies: a novel parameter for assessing esophageal bolus transit. Am J Physiol Gastrointest Liver Physiol. 2014;307:G158-63.

24. Lin Z, Carlson DA, Dykstra K, et al. High-resolution impedance manometry measurement of bolus flow time in achalasia and its correlation with dysphagia. Neurogastroenterol Motil. 2015;27:1232-8.

25. Singendonk MM, Omari TI, Rommel N, et al. Novel pressure-impedance parameters for evaluating esophageal function in pediatric achalasia. J Pediatr Gastroenterol Nutr. 2018;66:37-42.

26. Loots C, van Herwaarden MY, Benninga MA, et al. Gastroesophageal reflux esophageal function, gastric emptying, and the relationship to dysphagia before and after antireflux surgery in children. J Pediatr. 2013;162:566-7300.

27. Di Nardo G, Di Lorenzo C, Lauro A, et al. Chronic intestinal pseudo-obstruction in children and adults: diagnosis and therapeutic options. Neurogastroenterol Motil. 2017;29:e12945.

28. Connor FL, Hyman PE, Faure C, et al. Interobserver variability in antroduodenal manometry. Neurogastroenterol Motil. 2009;21:500-7, e3.

29. Desipio J, Friedenberg FK, Korimilli A, et al. High-resolution solid-state manometry of the antropyloroduodenal region. Neurogastroenterol Motil. 2007;19:188-95

30. Kellow JE, Borody TJ, Phillips SF, Tucker RL, Haddad AC. Human interdigestive motility: variations in patterns from esophagus to colon. Gastroenterology. 1986;91:386-95.

31. Faure C, Goulet O, Ategbo S, et al. Chronic intestinal pseudoobstruction syndrome: clinical analysis, outcome, and prognosis in 105 children. French-speaking group of pediatric gastroenterology. Dig Dis Sci. 1999; 44:953-9.

32. Fell JM, Smith VV, Milla PJ. Infantile chronic idiopathic intestinal pseudo-obstruction: the role of small intestinal manometry as a diagnostic tool and prognostic indicator. Gut. 1996;39:306-11.

33. Knowles CH, Lindberg G, Panza E, De Giorgio R. New perspectives in the diagnosis and management of enteric neuropathies. Nat Rev Gastroenterol Hepatol. 2013;10:206-18.

34. Ambartsumyan L, Rodriguez L, Morera C, Nurko S. Longitudinal and radial characteristics of intra-anal pressures in children using 3D high-definition anorectal manometry: new observations. Am J Gastroenterol. 2013; 108:1918-28.

35. Vitton V, Ben Hadj Amor W, Baumstarck K, Grimaud JC, Bouvier M. Water-perfused manometry vs three-dimensional high-resolution manometry: a comparative study on a large patient population with anorectal disorders. Colorectal Dis. 2013;15:e726-31.

36. Banasiuk M, Banaszkiewicz A, Dziekiewicz M, Załęski A,A Albrecht P. Values from three-dimensional high-resolution anorectal manometry analysis of children without lower gastrointestinal Symptoms. Clin Gastroenterol Hepatol. 2016;14:993-1000000.

37. Siddiqui A, Rosen R, Nurko S. Anorectal manometry may identify children with spinal cord lesions. J Pediatr Gastroenterol Nutr. 2011;53:507-11.

38. Bassotti G. Colonic manometry: for children only? A typical case of paradoxical motility. Am J Gastroenterol. 2003;98:949-50.

39. Liem O, Burgers RE, Connor FL, et al. Solid-state vs water-perfused catheters to measure colonic high-amplitude propagating contractions. Neurogastroenterol Motil. 2012;24:345-e167.

40. El-Chammas KI, Tipnis NA, Simpson PM, Sood MR. Colon high-resolution manometry: using pressure topography plots to evaluate pediatric colon motility. J Pediatr Gastroenterol Nutr. 2014;59:500-4.

41. Pensabene L, Youssef NN, Griffiths JM, Di Lorenzo C. Colonic manometry in children with defecatory disorders. Role in diagnosis and management. Am J Gastroenterol. 2003;98:1052-7.

42. van den Berg MM, Di Lorenzo C, Mousa HM, et al. Morphological changes of the enteric nervous system, interstitial cells of cajal, and smooth 
muscle in children with colonic motility disorders. J Pediatr Gastroenterol Nutr. 2009;48:22-9.

43. Rodriguez L, Nurko S, Flores A. Factors associated with successful decrease and discontinuation of antegrade continence enemas (ACE) in children with defecation disorders: a study evaluating the effect of ACE on colon motility. Neurogastroenterol Motil. 2013;25:140-e81.

44. van den Berg MM, Di Lorenzo C, van Ginkel R, Mousa HM, Benninga MA. Barostat testing in children with functional gastrointestinal disorders. Curr Gastroenterol Rep. 2006;8:224-9.

45. Villarreal J, Sood M, Zangen T, et al. Colonic diversion for intractable constipation in children: colonic manometry helps guide clinical decisions. J Pediatr Gastroenterol Nutr. 2001;33:588-91.

46. Youssef NN, Pensabene L, Barksdale E Jr., Di Lorenzo C. Is there a role for surgery beyond colonic aganglionosis and anorectal malformations in children with intractable constipation? J Pediatr Surg. 2004;39:73-7.

47. Christison-Lagay ER, Rodriguez L, Kurtz M, et al. Antegrade colonic enemas and intestinal diversion are highly effective in the management of children with intractable constipation. J Pediatr Surg. 2010;45:213-9.

48. Bonilla SF, Flores A, Jackson CC, Chwals WJ, Orkin BA. Management of pediatric patients with refractory constipation who fail cecostomy. J Pediatr Surg. 2013;48:1931-5.

49. Di Lorenzo C, Flores AF, Hyman PE. Age-related changes in colon motility. J Pediatr. 1995;127:593-6.

50. Bassotti G, de Roberto G, Castellani D, Sediari L, Morelli A. Normal aspects of colorectal motility and abnormalities in slow transit constipation. World J Gastroenterol. 2005;11:2691-6.

51. Bampton PA, Dinning PG. High resolution colonic manometry-what have we learnt? A review of the literature 2012. Curr Gastroenterol Rep. 2013;15:328.

52. Arkwright JW, Underhill ID, Dodds KN, et al. A composite fibre optic catheter for monitoring peristaltic transit of an intra-luminal bead. J Biophotonics. 2016;9:305-10.

53. Dinning PG, Wiklendt L, Maslen L, et al. Colonic motor abnormalities in slow transit constipation defined by high resolution, fibre-optic manometry. Neurogastroenterol Motil. 2015;27:379-88.
54. Lee YY, Erdogan A, Rao SS. How to perform and assess colonic manometry and barostat study in chronic constipation. J Neurogastroenterol Motil. 2014;20:547-52

55. Saad RJ, Hasler WL. A technical review and clinical assessment of the wireless motility capsule. Gastroenterol Hepatol (N Y). 2011;7:795-804

56. Hasler WL. The use of smartPill for gastric monitoring. Expert Rev Gastroenterol Hepatol. 2014;8:587-600.

57. Saad RJ. The wireless motility capsule: a one-stop shop for the evaluation of GI motility disorders. Curr Gastroenterol Rep. 2016;18:14.

58. Arbizu RA, Rodriguez L. Electrogastrography, breath tests, ultrasonography, transit tests, and smartpill. In: Faure CD, Thapar N, editor. Pediatric Neurogastroenterology. ${ }^{\text {nd }}$ ed. Switzerland: Springer International Publishing; 2017. p. 174

59. Faure $C D$, Thapar N, editor. Barostat and other sensitivity tests. In: Pediatric Neurogastroenterology. $2^{\text {nd }}$ ed. Switzerland: Springer International Publishing; 2017. p. 153.

60. Hirano I, Pandolfino JE, Boeckxstaens GE. Functional lumen imaging probe for the management of esophageal disorders: expert review from the clinical practice updates committee of the AGA institute. Clin Gastroenterol Hepatol. 2017;15:325-34.

61. Carlson DA. Functional lumen imaging probe: the FLIP side of esophageal disease. Curr Opin Gastroenterol. 2016;32:310-8.

62. Varni JW, Wilcox KT, Hanson V, Brik R. Chronic musculoskeletal pain and functional status in juvenile rheumatoid arthritis: an empirical model. Pain. 1988;32:1-7.

63. Carlson DA, Lin Z, Kahrilas PJ, et al. The functional lumen imaging probe detects esophageal contractility not observed with manometry in patients with achalasia. Gastroenterology. 2015;149:1742-51.

64. Carlson DA, Lin Z, Rogers MC, et al. Utilizing functional lumen imaging probe topography to evaluate esophageal contractility during volumetric distention: a pilot study. Neurogastroenterol Motil. 2015;27:981-9. 